\title{
Multi-species Action Plan for African-Eurasian vultures (MsAP) - a commentary
}

\section{P.J. Mundy}

National University of Science and Technology, Bulawayo, Zimbabwe.

Botha, A. J., Andevski, J., Bowden, C. G. R., Gudka, M., Safford, R. J., Tavares, J. and Williams, N. P. (2017). Multi-species Action Plan to Conserve African-Eurasian Vultures. CMS Raptors MOU Technical Publication No. 5. CMS Technical Series No. 35. Coordinating Unit of the CMS Raptors MOU, Abu Dhabi, United Arab Emirates.

This Plan was accepted at the $12^{\text {th }}$ Conference of the Parties of the Convention for the Conservation of Migratory Species (CMS) in October 2017, at the CMS meeting in Philippines. It has a 12-year time line and will evaluate itself in 2023 and 2029. So we are already a quarter of the way through the period; whooah! what's happened so far? (The only impactful thing at the moment, May 2020, world-wide it seems, is the damned Corona virus). Just as I was writing this commentary so I learned of the "Strategic Implementation Plan (2020 - 2023)", produced in February 2020, which incorporates a "report on implementation to date". Scope for another commentary perhaps?

The Plan encompasses 128 countries from Afghanistan to Zimbabwe, in Africa, Asia, Europe and the Middle East. It considers 15 out of the species of Old World vultures, the omission being the Palm-nut Vulture Gypohierax angolensis because it is more of a frugivore rather than an "obligate scavenger" (it does scavenge of course). The authors are André Botha, Jovan Andevski, Chris Bowden, Masumi Gudka, Roger Safford, José Tavares and Nick P. Williams, under the management of NP Williams and J Rennell. The authors have actually done a helluva job of compilation (more below) - some of their Tables go over several pages. They use del Hoyo \& Collar (2014), Volume 1, as their source of taxonomy and sequence of species; the sequence is curious, but never mind now. The Plan aims at "conservation action.....led by Governments and supported by all stakeholders." Colloquially it's called the "Vulture MsAP". I found the Plan tricky to download and there are two citations, but Sofi Hinchliffe advised me on the correct one (Botha et al. 2017).

All the vultures are called "migratory" in some way or another, seemingly after Keith Bildstein (2006, his Table 2), though he excludes the Slender-billed Vulture Gyps tenuirostris and White-headed Vulture Trigonoceps occipitalis from his list. To consider all of them as migratory is certainly stretching a point: the Cape Griffon $G$. coprotheres for example, is nomadic rather than migratory in the way we understand migratory as meaning to move from A to B and back again, annually.

The Plan has three main objectives: (i) to rapidly halt the current population declines, (ii) to reverse the trends and return the species to a favourable situation, and (iii) to provide guidelines. In the end (see below) 124 actions are recommended, of which 17 are termed "essential" and to be done immediately. The interim steering group was established in January 2016 with the final draft (and numbered as 4/33 rather than 5/35, which caused my confusion) on the table in October 2017; this is fast work! The MsAP is to be used as a guide for the preparation of "national vulture conservation action plans." During this two-year period four regional workshops were convened, with 212 participants in total; they were at Senegal (at the PAOC in October 2016), Extremadura in Spain, Mumbai in India, and Sharjah in UAE. This in itself is a considerable logistic achievement.

Following del Hoyo \& Collar (2014), everybody is a "vulture" including the Griffon Vulture Gyps fulvus of Eurasia and North Africa, but curiously excepting the Himalayan Griffon G. himalayensis. I have made the case before that in effect Gyps means "Griffon" (Mundy 2002), but so far not to be. 
There then follow detailed descriptions of all 15 species, each with a photograph and a very detailed map; this latter is based on five categories - (breeding) resident, breeding visitor, non-breeding, extinct, and probably extinct (called "possibly" in Annex 2). There is also a bold/brave attempt at putting numbers to all the species, as listed:

\begin{tabular}{|c|c|c|}
\hline Species & Population & Comments \\
\hline Bearded Vulture & $\begin{array}{l}2,000-10,000 \\
(1300-6700 \text { mature individuals })\end{array}$ & $\begin{array}{l}\text { In Europe, up to } 749 \text { pairs }=1600 \\
\text { mature individuals }\end{array}$ \\
\hline Egyptian Vulture & $18,000-57,000$ & $(12,000-38,000$ mature ind.) \\
\hline Red-headed Vulture & $3,500-15,000$ & \\
\hline White-headed Vulture & 5,500 & $(3,685$ mature ind., $2,500-9,999)$ \\
\hline Hooded Vulture & 197,000 individuals & \\
\hline Himalayan Griffon & $66,000-334,000$ & \\
\hline White-rumped Vulture & 8,000 ind. & $\begin{array}{l}\text { Decline in India of about } 99.9 \% \\
\text { between } 1992 \text { and } 2007\end{array}$ \\
\hline White-backed Vulture & 270,000 individuals & $\begin{array}{l}\text { Currently estimated at } 270,000 \\
\text { and rapidly declining. }\end{array}$ \\
\hline $\begin{array}{l}\text { Indian Vulture } \\
\text { ("the taxonomy was } \\
\text { clarified distinguishing the } \\
\text { two species") }\end{array}$ & 12,000 individuals & $\begin{array}{l}\text { Decline of more than } 97 \% \text { in India } \\
\text { in a } 10-15 \text { year period beginning } \\
\text { in the } 1990 \text { s. }\end{array}$ \\
\hline Slender-billed Vulture & $1,500-3,750$ individuals & $\begin{array}{l}\text { Decline of more than } 95 \% \text { in } 10- \\
15 \text { years. }\end{array}$ \\
\hline Cape Vulture & 4,700 pairs (9400 mature ind.) & Stable or increasing \\
\hline Rüppell's Vulture & 22,000 individuals & \\
\hline Griffon Vulture & $80,000-120,000$ individuals & Increasing \\
\hline Cinereous Vulture & $15,600-21,000$ individuals & Stable to slightly increasing \\
\hline Lappet-faced Vulture & $\begin{array}{l}8,500 \text { individuals in Africa } \\
600 \text { pairs in Arabian peninsula }\end{array}$ & \\
\hline
\end{tabular}

On the whole, these accounts are good and generally accurate. But 'funnies' if not errors occur here and there; for example the African White-backed Vulture is assessed at 270,000 individuals. In fact this is my guesstimate in Mundy et al. 1992: 135, so how can the species be "rapidly declining" by 2017, 25 years later, still with the same number? How does Europe get up to 749 pairs for the Bearded Vulture? Note that Europe includes western Russia northwards from the Caucasus mountains, but not Turkey which is in Asia Minor (Middle East) nor Armenia, Azerbaijan and Georgia which are south of the Caucasus. The Caucasus population is said to be huge; thus, included in Europe, I make the arithmetic $410-468$ pairs. Therefore again, how could the species be as low as 2000 birds? For the White-headed Vulture, Murn et al. (2016) estimated just under 5500 individuals; where does 2500 - 9999 come from? For the Rüppell's Griffon Gyps rueppelli I had guesstimated 30,000 birds (Mundy et al. 1992: 111), in halcyon days, so where does 22,000 come from? And for the Lappet-faced Vulture Torgos tracheliotos I had proposed 8000 birds in Africa (op. cit. p.163), which has now increased to 8500 ! I said that the attempt at numbering was bold/brave, but could it have been done more carefully, please, with greater precision? Don't the numbers need justification?

These species' accounts can be taken as good up-todate descriptions on each, and hopefully would be used as such in the future. Note the sizes of the declines for the three Indian Gyps vultures; presumably these percentages should now be used by all of us.

Bewilderingly there are different units in use here. In particular, there are "mature individuals" and 
"individuals". In Mundy et al. (1992: 71) we changed present listing the authors have used an addition of adults to total birds for a species by adding one-third, one-half, which possibly originates from Murn et al. which allows for immatures and juveniles; in the (2016: 1096), who in fact used $46 \%$.

The Plan lists several threats to vultures, viz:

- Poisoning (human-wildlife conflict/poachers of elephants/belief-based use (superstitions). Lead is not mentioned here, but it is later. Nor are NSAIDs.)

- Habit loss and degradation

- Decreasing food availability

- Fragmentation of remaining populations

- Human disturbance

- Collisions with wind turbines and powerlines

- Electrocution on electricity infrastructure.

A few others (minor?) are listed, such as drowning in circular reservoirs, but are seen as having limited impact.

Later on in the Plan, poisoning itself is disentangled as follows:

- Unintentional (secondary) poisoning:

$\circ$ Human-wildlife conflict

○ Problem animal control

- NSAIDs and other veterinary medicines

$\circ \quad$ Lead poisoning (from ammunition)

$\circ$ Bioaccumulation.

- Direct/targeted poisoning:

○ Belief-based use and bushmeat

○ "sentinel" poisoning (i.e. poisoning of a poached elephant).

Eventually we arrive at Part 7 of the Plan, "Framework for action", which is the nitty-gritty of it, and now getting specific. We start with 12 Objectives:

- $\quad$ Reduce mortality caused unintentionally by vertebrate control

- Reduce mortality caused by NSAIDs

- Phase out the use of lead ammunition

- Halt trade in vulture parts

- Halt sentinel poisoning by poachers (the Plan repeatedly mentions elephants and buffalos)

- Reduce mortality from electrocution

- Reduce mortality from collisions

- Safe food available to sustain healthy vulture populations

- Suitable habitat for nesting, roosting and foraging

- Reduce levels of human disturbance

- Cross-cutting actions aimed at knowledge gaps

- Promotion and implementation of the Vulture MsAP. 
This is a fully comprehensive list of Monitoring, Education \& Awareness, Direct objectives/intentions, which no doubt feature on the 'wish-list' of most of the countries in the MsAP.

Now at last we come to Tables 6 and 7, both of which are matrices of awe-inspiring size. Table 6 has the heading "Framework of conservation actions for African-Eurasian vultures". It has seven columns: Results, Actions, Category, Time frame (years), Priority, Stakeholders to do the action, and nine Regions (these are North, West, East and southern Africa, Europe and Central Asia, Middle East, South Asia, East Asia and South-east Asia). It uses 33 results, 124 actions, four categories (Research \&

Conservation Action, and Policy \& Legislation), the time frames are from one to 12 years, there are three Priorities (Essential, High and Medium), a minimum of 35 stakeholders, and the above nine regions. The 12 Objectives are over-laid onto the matrix, and the 124 Actions are fitted into each of them. Some of the stakeholders are government, NGOs, universities, research institutions, general public, hunters, pharmaceutical industry, etc. Among the Priorities, there are 17 Essentials, which are highlighted in pink for easy location.

In brief, these 17 Essential Priorities for conservation action are as follows:

i. "Conduct an overall situation analysis of wildlife poisoning associated with human-wildlife conflict..." $1-6$ years, in all nine regions.

ii. "Awareness campaigns on the poisons, including... (b) likely ineffectiveness of poisoning as a problem animal control technique". I wonder how true this (b) is? Certainly, the technique kills a lot of carnivores, and of course non-targets such as the vultures, and it assuages the anger of the livestock farmer. With the ease of getting the chemicals, that's why it's such a popular method. $1-12$ years, in all regions.

iii. "Establish protocols and train and support relevant agency staff to respond..." 1- 6 years, in 8 regions (- East Asia). This is certainly happening in East and southern Africa (and elsewhere?)

iv. "Review, introduce and enforce strict penalties for illegal wildlife poisoning..." $1-6$ years, in all regions.

v. "Prohibit or withdraw veterinary use of diclofenac, ketoprofen and aceclofenac ... substitute with ... meloxicam...." 1- 6 years, in all regions. With the entry of diclofenac (at least) into Europe and possibly into Africa, then its withdrawal has assumed urgent proportions. Is it being prohibited in Europe?

vi. "Develop an approval process....for all veterinary NSAIDs..." $1-6$ years, in all regions.

vii. "Promote implementation of CMS $11.15 \ldots$ voluntary lead ... bans..." 1 - 3 years, in 8 regions (West Africa).

viii. “...engagement and dialogue...belief-based use of vultures..." 1- 6 years, in three regions (W, E, southern Africa). Traditional healers and their Associations are the target here, to get them onside rather than just to punish. Work on this is ongoing in southern Africa.

ix. "Expand the poisoning response training programmes" $1-12$ years, in two regions (E, southern Africa).

x. "... sensitivity mapping...energy infrastructure...electrocution" $1-3$ years, in all regions.

xi. “...implementation of CMS guidelines...retro-fitting...” $1-12$ years, in all regions.

xii. “... sensitivity mapping...collision risk ..." $1-3$ years, in all regions.

xiii. “...energy infrastructure...collision... retro-fitting..." 1- 12 years in all regions.

xiv. "Census 2018-19 and repeated in 2028-29...size...productivity..." 1 - 12 years, in all regions. What does this mean, of all species in all regions?! Phew! 
xv. "Total Economic Value study... ecosystem services...eco-tourism attraction." $1-3$ years, in all regions. This is a good one, but (only?) South Africa is likely to do it in Africa.

xvi. "Develop VSZ criteria...to address all critical threats..." $1-12$ years, in all regions. This is another good one, which incorporates most/all of the above.

xvii. "...coordinate implementation of the Vulture MsAP". 1 -2 years, in all regions. Surely to be done on a regional basis?

Thus it can be seen that the time-line for action (xvii) has passed, and that for four others, (vii), (x), (xii) and (xv) is imminent, at the time of writing (May 2020). Action (vii) on lead ammunition is certainly urgent, and one wonders how many rifle associations/gun clubs/and military (?) have been contacted? Any results from the dialogues?

Then we get to Table 7, "Suggested priority results and actions per Range State". All 33 results (see Table 6) are offered to all the countries, using eight priorities in different colours: critical (blue), high (green), medium (red), low (brown), needs to be assessed (grey), no information (yellow), not known (black), and not relevant (white). But curiously, mauve and purple are in the Table too. My own country, Zimbabwe, has one critical result, 11.1, being "Increased understanding of basic biological and ecological parameters and threats influencing vulture populations." This seems curious, we have been studying and watching vultures for decades, since at least 1972. Why do we want more of it? Zimbabwe is a country with poisons and a hunting industry (both citizen and international safari hunts on elephants, lions, leopards, buffaloes, antelopes, etc.), so priorities (i), (ii), (vii), (viii) and (xvi) are more critical in today's environment. Mozambique, next door to Zimbabwe, has no less than eight "critical" actions, and Namibia has six. This is more than India, Nepal and Pakistan which all have (the same) five!

Section 8, "International Coordination of Implementation" deals with the Overarching Coordinator, Regional Coordinators, and others. Apart from wondering who these people might be at present, in Africa we will miss an opportunity this year 2020 with the postponement of the $15^{\text {th }}$ Pan-African Ornithological Congress to the end of 2021 due to the Coronavirus, four years into the Plan. How will the coordinators substitute for this 'hole'? Nevertheless section 8.5.2 has an important paragraph - "Vulture Range States often include significant areas of land where management can be influenced in favour of vultures, working with land owners and land managers to encourage positive action for vultures. This is the principle behind the concept of Vulture Safe Zones." Indeed! In Africa, and certainly in Zimbabwe, the issue is not land "owners", nobody can now own land in the countryside (through a recent decree), but rather land holders or occupiers. The issue of land tenure is something of a political 'hot-potato', and subject to much debate. Now that owners are merely holders/occupiers, one wonders how much influence/control the relevant Ministry will have over them. In fact in Zimbabwe (and South Africa?) this is a critical issue; and the rest of Africa?

Finally, for my commentary, I come to Annex 2.1, "Range and status of the 15 species covered by the vulture MsAP." All species are laid against all countries, for another tour de force, which promises to be a useful 'ready-reckoner' for the places where each vulture lives. There are seven categories here, being resident (green), breeding visitor (yellow), nonbreeding (blue), extinct since 1985 (red), possibly extinct (pink), vagrant (light blue), and no data (white). In Section 3, each map (Figures 3 - 17) has five categories, and as mentioned before "possibly" here is "probably" there. I picked out a couple of omissions in South Africa the Egyptian Vulture is said to be extinct whereas it is at least a vagrant and personally I think it is rather a breeding resident; in Zimbabwe the Rüppell's Griffon has visited as a vagrant; and in Kenya the Eurasian Griffon is a vagrant (Clark 2001), and will it become more common there?

In Annex 3, "Threat maps per species", a maximum of seven threats is attached to four species, being White-backed, Lappet-faced and Hooded Vultures in Africa, and Cinereous Vulture. As one example, the 
threats for the White-backed Vulture are listed as: belief-based poisoning, unintentional poison baits, sentinel poisoning, collisions, electrocution, food decline and habitat degradation.

So overall the Plan is a good summary (if at 166 pages it can be called a summary) of the state of the Old World vultures, their threats, and the proposed conservation actions needed to return each one to a reasonable even favourable status. In fact it is a very detailed Plan with, as mentioned above, awe-inspiring matrices. Always of course the proof of the pudding is in the eating: will it be referred to, will it be used, will it be our blue-print, if it's in hard copy will it become 'dog-eared', and so on? Acknowledging that there are so few government ornithologists in Africa (outside of South Africa), and in Asia too?, whose government desk or computer will the Plan sit on? I'd hazard a guess that it will get lost there, whether in hard copy or digital, wherever it is. The actual drivers of the Plan must be the BirdLife International (BLI) network of countries. Of course the Plan had to emphasise governments, as it did, because the CMS itself is an international forum of countries (= governments), and the rest of us are 'observers'. If one has a high opinion of one's government because it is responsive to the urgencies of the MsAP, climate change, now Corona virus, poverty, income disparity, health service, then all well and good, we might see some action. But the ornithologists themselves are mostly with the BLI network, and the onus is on them to "understand" the vultures, lead the way, coordinate, and bring the government along with them.

Let's hope it can be done; we are already one-quarter of the way through.

\section{References:}

Bildstein, K.L. (2006). Migrating raptors of the world. Cornell University Press, Ithaca. 320 pp.

Botha, A., Andevski, J., Bowden, C., Gudka, M., Safford, R., Tavares, J. \& Williams N.P. (2017). Multi-species Action Plan for African-Eurasian vultures. CMS Raptors MOU Technical Publication No. 5, CMS Technical Series No. 35. Coordinating Unit of the CMS Raptors MOU, Abu Dhabi, U.A.E. 166 pp.

Clark, W.S. (2001). First record of European Griffon Gyps fulvus for Kenya. Bulletin African Bird Club 8: 59. del Hoyo, J. \& Collar, N.J. (eds)(2014). Illustrated checklist of the birds of the world, Volume 1 Non-passerines. Lynx Edicions, Barcelona. 903 pp.

Mundy, P.J. (2002). When is a vulture a griffon? Vulture News 46: 20-23.

Mundy, P., Butchart, D., Ledger, J. \& Piper, S. (1992). The vultures of Africa. Acorn Books and Russel Friedman Books, Randburg and Halfway House (South Africa). 460 pp.

Murn, C., Mundy, P., Virani, M.Z., Borello, W.D., Holloway, G.J. \& Thiollay, J-M. (2016). Using Africa's protected area network to estimate the global population of a threatened and declining species: a case study of the Critically Endangered White-headed Vulture Trigonoceps occipitalis. Ecology and_Evolution 6: 10921103. 